International Journal of Rotating Machiner

1997, Vol. 3, No. 4, pp. 249-258

Reprints available directly from the publisher

Photocopying permitted by license only
(C) 1997 OPA (Overseas Publishers Association)

Amsterdam B.V. Published under license under the Gordon and Breach Science Publishers imprint Printed in India

\title{
Hysteresis in Oil Flow through a Rotating Tube with Twin Exit Branches
}

\author{
SUN-WEN CHENG* and WEN-JEI YANG
}

Department of Mechanical Engineering and Applied Mechanics, University of Michigan, Ann Arbor, MI 48109, USA

(Received in final form 1 May 1997)

\begin{abstract}
Oil enters a horizontal rotating tube through a radially-attached duct at one end. The tube with the other end closed is attached with radial twin exit branches permitting oil to exit into open air. Air begins to enter through one of the two branches into the tube when its rotational speed reaches certain critical values. An experimental study is performed to investigate this air-oil two-phase flow behavior. Both the tube and the branches are transparent to allow illumination and flow visualization during spin-up and spin-down processes. The branch-totube diameter ratio, rotational speed, and oil flow rate are varied. Changes in oil flow rates are measured as a function of rotational speed. A comparison is made between cases of a varying total oil flow rate due to rotation effects and a constant one under control. It is disclosed that cavitation in oil flow is induced by air entering the branches opposite to the ejecting oil flow. Subsequently air bubbles progress in the tube. The origin of this intrusion depends on the hydraulic head loss of the piping system. This study can be applied to oil lubrication analysis of rotating machinery, such as automotive transmission lines.
\end{abstract}

Keywords: Rotating tube, Twin exit branches, Cavitation, Air-oil flow, Hysteresis, Lubrication

\section{INTRODUCTION}

Efficiency is one of the most important concerns in the design of rotating machinery. High-speed rotating machinery, including jet turbines, power generators and automotive transmission systems, need working fluids to protect key parts in the system and still fulfill the efficiency requirement. To meet these challenges, the durability of such machines relies on an adequate supply of lubricant or coolant. For the automotive transmission in automobiles, an optimized flow rate of lubricating oil, which runs through the hollow shaft serving as a flow passage, can prevent wear and seizure, dissipate heat, reduce friction, and enhance efficiency. On the other hand, an over-supply of lubricating oil may cause agitation loss in the automotive transmission. The needed amount of lubricating oil is difficult to determine because of the structural complexity of the automotive transmission and

\footnotetext{
* Corresponding author.
} 
its operation under rotating conditions. Among various factors that can reduce the supply of oil, cavitation is perhaps the most important cause.

Cavitation is caused by either the physical properties of liquids or the special shapes of flow passages. There are two categories of cavitation: vaporous cavitation and gaseous cavitation. The origin and effects of cavitation, and variables affecting its development, were investigated by Backe and Riedel (1972) and Riedel (1972). They found that cavitation in oil flow is susceptible to periodic changes in either pressure or flow rate. Cavitation may be triggered in hydraulic equipment by flow constrictors, such as orifices and valves. The consequence of flow constrictors on the unsteady characteristics of oil flow was studied by Ishihara et al. (1975). Because of its low vapor pressure and high air content, mineral oil used in hydraulic equipment tends to disclose gaseous cavitation. In the present study, cavitation is caused by the introduction of outside air into the rotating system with hysteresis of air-oil flow.

Hysteresis in air-oil flow is originated by the compressibility of gases which are brought into the system by cavitation and contribute a viscous damping effect to flow dynamics. Hysteresis of cavitation in an unsteady oil flow through sharpedged orifices was detected with the aid of scattered laser beams by Ishihara et al. (1979). They found hysteresis between the incipience and desinence of vaporous cavitation, following the disappearance of gaseous cavitation in oil flow initially with a high air content, related to pressure difference. They also observed gaseous cavitation in the annular stratified and dispersed flow regimes and vaporous cavitation in the bubbly or froth flow regime. However, little attention has been paid to hysteresis of air-oil two-phase flow in rotating ducts so far.

Hysteresis in air-oil flow is still obscure in comprehensive pipelines, as in an automotive transmission line, although cavitation can be predicted for a single flow part. The effect of cavitation on oil flow rate has been analyzed with theoretical modeling done by Backe (1973) and Kojima et al. (1991). Predictions of oil flow rate generally agree with experimental data but significant deviations remain.

This paper presents an experimental study of the hysteresis in air-oil flow caused by cavitation in a horizontal rotating tube with a radial entrance and twin branches for oil exit, as shown in Fig. 1. Air cavitation and two-phase flow in both the tube and the branches were observed by flow visualization. Flow rates and inlet gauge pressure were also measured under the same operating conditions.

\section{EXPERIMENTAL APPARATUS AND PROCEDURE}

A schematic of the experimental setup is shown in Fig. 2. It consists of a hydraulic system, an oil inlet assembly, a test section, and a driving system (Fig. 1 and Table I).

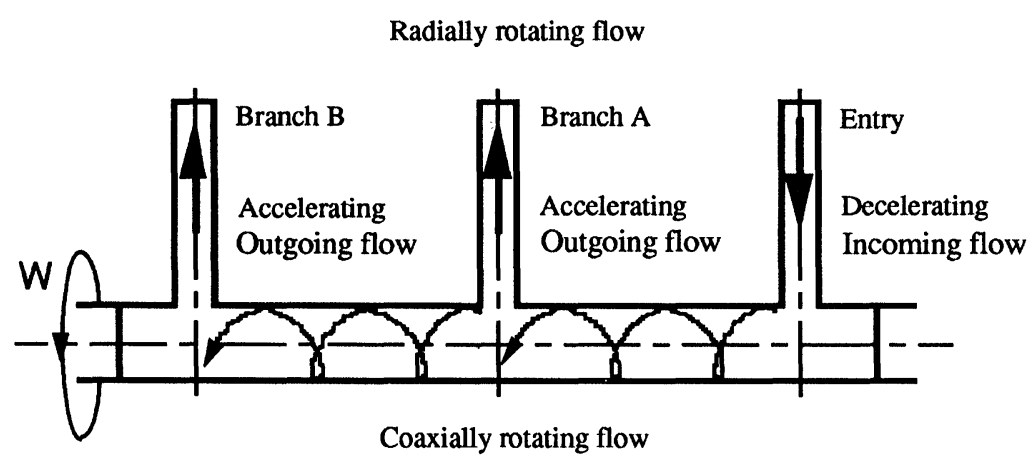

FIGURE 1 Flow inside a rotating tube with twin exit branches. 


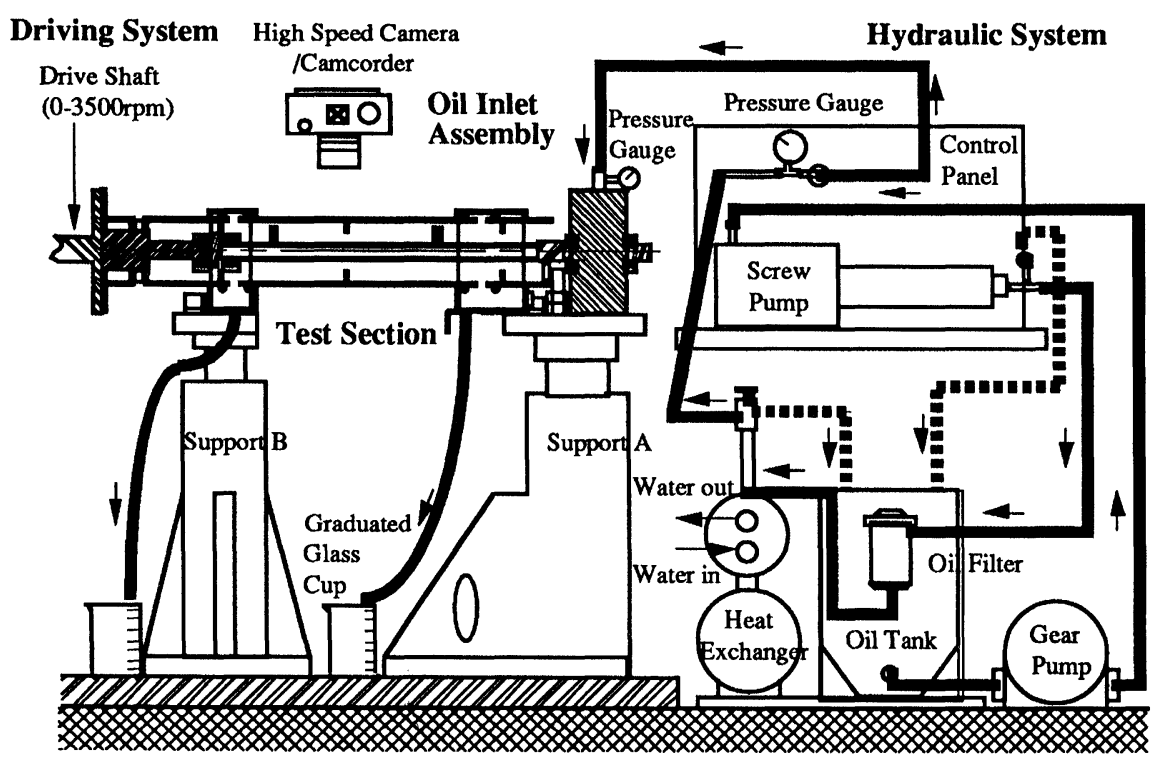

FIGURE 2 Schematic of experimental setup.

TABLE I Dimensions of inner test sections

\begin{tabular}{|c|c|c|c|c|c|}
\hline Test section & & Entrance & Branch A & Branch B & Shaft \\
\hline$\# 1$ & ID: & $d_{\mathrm{in}}: 6.35 \mathrm{~mm}$ & $d_{\mathrm{A}}: 3.175 \mathrm{~mm}$ & $d_{\mathrm{B}}: 3.175 \mathrm{~mm}$ & $d_{\mathrm{s}}: 12.7 \mathrm{~mm}$ \\
\hline$\# 2$ & & $6.35 \mathrm{~mm}$ & $6.35 \mathrm{~mm}$ & $3.175 \mathrm{~mm}$ & $12.7 \mathrm{~mm}$ \\
\hline \#3 & & $6.35 \mathrm{~mm}$ & $3.175 \mathrm{~mm}$ & $6.35 \mathrm{~mm}$ & $12.7 \mathrm{~mm}$ \\
\hline$\# 4$ & & $6.35 \mathrm{~mm}$ & $6.35 \mathrm{~mm}$ & $6.35 \mathrm{~mm}$ & $12.7 \mathrm{~mm}$ \\
\hline Length: & & $25.4 \mathrm{~mm}$ & $25.4 \mathrm{~mm}$ & $25.4 \mathrm{~mm}$ & $469.9 \mathrm{~mm}$ \\
\hline Distance: & & $l_{\text {in }-\mathrm{A}}: 203.2 \mathrm{~mm}$ & $l_{\mathrm{A}-\mathrm{B}}: 2$ & $2 \mathrm{~mm}$ & \\
\hline
\end{tabular}

The hydraulic system contains oil tanks, pumps, pipelines and bypasses, valves and a water-cooled heat exchanger. The last one is used to control the oil temperature within $31.0-33.0^{\circ} \mathrm{C}$ and to minimize viscosity effect on flow rates. The remaining pieces are used to maintain total oil flow rate into the oil inlet assembly and back to the base oil tank.

The oil inlet assembly consists of a stationary pressure chamber, a rotary shaft, lip seals, and double-sealed ball bearings. The rotary shaft is drilled hollow through one end without penetrating the other. Another circular duct is drilled perpendicular to the shaft so that oil flow runs toward the shaft centerline and turns $90^{\circ}$ into the test section.
The test section is made of transparent, lightweight, thin acrylic tubes $(3.175 \mathrm{~mm}$ thick) permitting flow visualization. It consists of two concentric tubes that rotate simultaneously. The inner tube is attached perpendicularly with the branches. Its upstream end is connected to the rotary shaft, and its downstream end to a spider flexible coupling connected to a drive shaft (explained later). The distance between the twin branches is fixed, but their inner diameters are varied. The outer tube is to lead oil flow into two stationary collectors that drain oil into a moveable tank, where a set of beakers may be used to measure the effluent flow rates. 
The driving system has a drive shaft transferring power from a dynamometer, monitored by a digital tachometer, to both the test section and the oil inlet assembly. The rotational speed has practically no deviation below $1800 \mathrm{rpm}$ and within $1 \%$ up to $2500 \mathrm{rpm}$. The maximum operating speed was restricted to protect the acrylic tubes.

Flow patterns in the branches including both front and side views were observed, together with the flow pattern in the inner tube. Flow patterns were recorded using a stroboscope and a camcorder with a high-speed shutter function.

The effluent flow rates were measured at intervals of $200 \mathrm{rpm}$ and up to $2500 \mathrm{rpm}$. More data were measured at certain speeds of interest. Air bubbles inside the system were purged prior to each test run. The flow rates were also measured at the following critical rotational speeds: at the appearance and disappearance of air bubble(s), at the instant an air pocket was formed or vanished, and at the moment oil flow became annular with air in

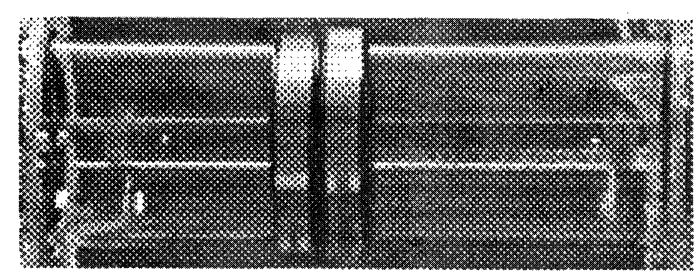

(a) WC $1=1000$ RPM

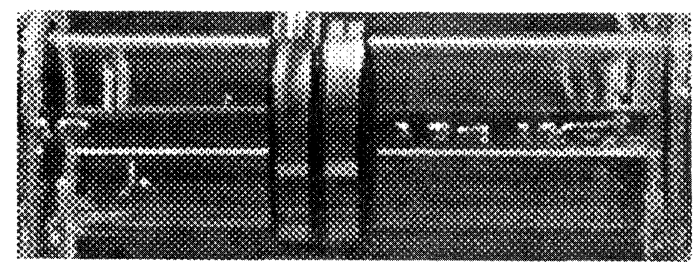

(b) Wc2=1050 RPM, +0.400 sec

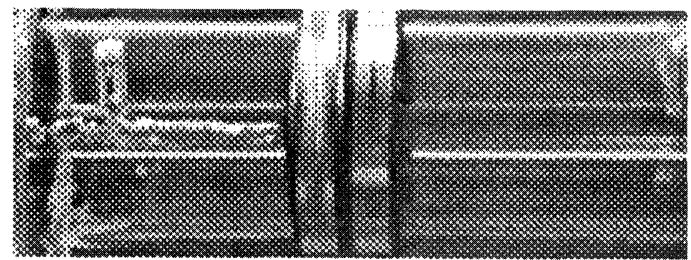

(c) Wc2=1050 RPM, +3.200 sec the core. The corresponding inlet gauge pressure was also recorded for reference.

\section{RESULTS AND DISCUSSION}

In the interest of brevity, only two cases of test Section \#2 (specified in Table I) are presented to show the effects of the Coriolis force on both oil flow rate and air-oil flow pattern. Case 1 has an approximately constant total oil flow rate $Q_{\mathrm{T}}$ (Figs. 3-5), while Case 2 keeps valves unaltered so that $Q_{\mathrm{T}}$ varies with rotational speed (Figs. 6-8). Figures 9 and 10 illustrate the oil flow rates and the inlet pressure versus the rotational speed at steady state, respectively.

When stationary, i.e. $0 \mathrm{rpm}$, the branches were placed horizontally to measure the effluent flow rates through the upstream and downstream branches $\mathrm{A}$ and $\mathrm{B}$. The ratio of $Q_{\mathrm{A}}$ to $Q_{\mathrm{B}}$ is not

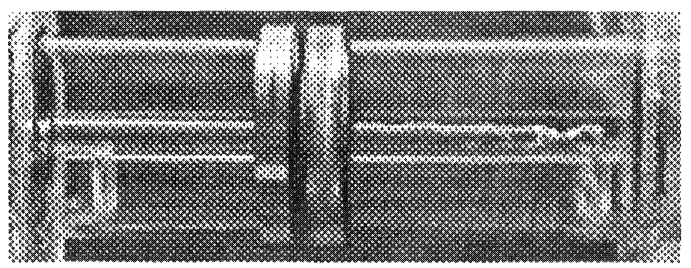

(d) $W=1100$ RPM

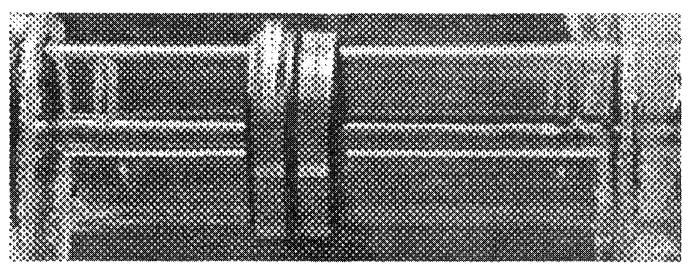

(e) $W C 3=1400$ RPM

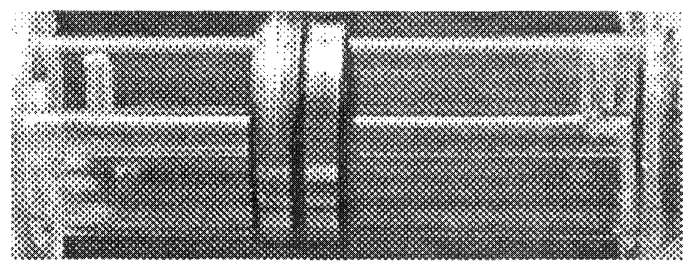

(f) $W=2500$ RPM

FIGURE 3 Flow patterns inside tube in spin-up process (Case 1) (ID: $\mathrm{d}_{\mathrm{in}}=\frac{1}{4}^{\prime \prime}, \mathrm{d}_{\mathrm{S}}=\frac{1}{2}^{\prime \prime}, \mathrm{d}_{\mathrm{A}}=\frac{1}{4}^{\prime \prime}, \mathrm{d}_{\mathrm{B}}=\frac{1}{8}^{\prime \prime} ; \mathrm{Q}=\mathrm{Q}_{\mathrm{T}}=0.3 \mathrm{GPM}$ ). 


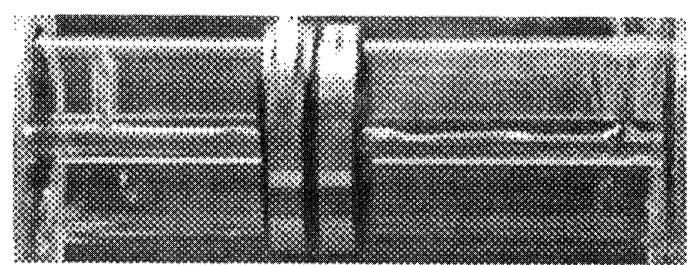

(a) $W=1000$ RPM

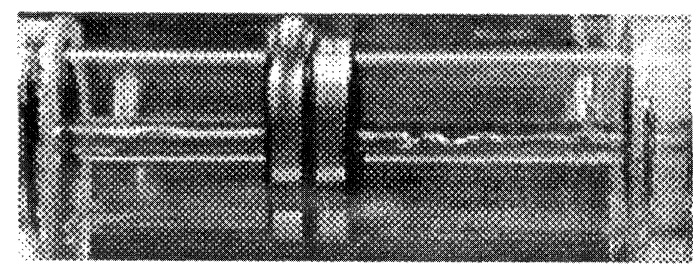

(b) Wc4=980 RPM, +0.000 sec
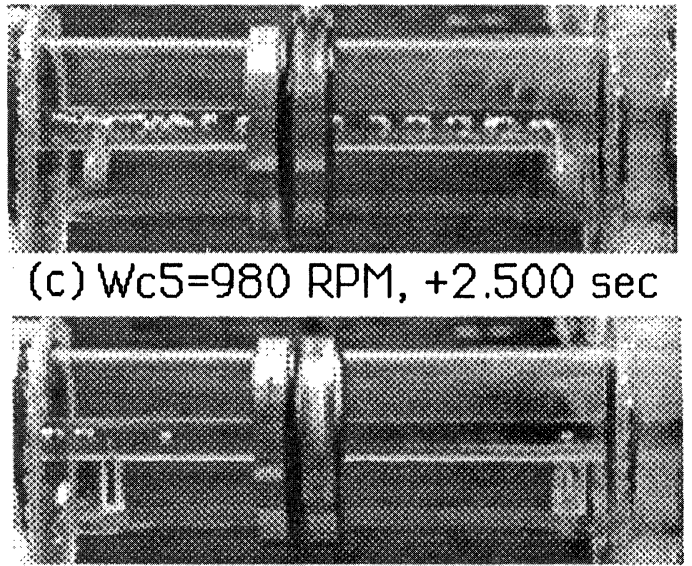

(d) $W C 6=970$ RPM

FIGURE 4 Flow patterns inside tube in spin-down process (Case 1).

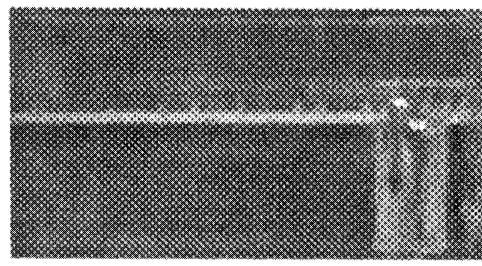

(a) WC2 $=1050 \mathrm{RPM},+0.000 \mathrm{sec}$

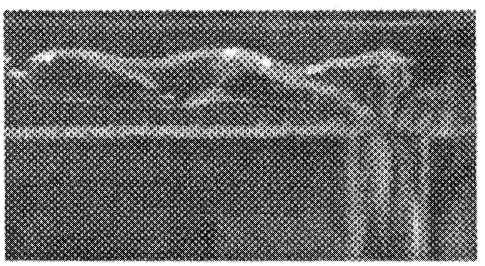

(b) $W c 2=1050$ RPM, $+0.400 \mathrm{sec}$

FIGURE 5 Flow patterns around Branch $\mathrm{A}$ in spin-up process (Case 1).

proportional to the ratio of their flow crosssectional areas, but is nearly equal to the result estimated by the hydrodynamically developing flow model associated with hydraulic head losses. The fully-developed laminar flow approach deviates less than $5 \%$ because of high oil viscosity and relatively long flow passages.

In the spin-up process, $Q_{\mathrm{T}}$ of Case 2 initially grows slightly larger due to a reduced apparent friction factor for a single-phase flow. This fact is similar to the conclusions drawn by White (1964) and Shchukin (1967). The $Q_{\mathrm{T}}$ gradually drops at higher rotational speeds $W$ because the centrifugal force acts in the rotating entrance duct (Fig. 9(b)).

Prior to the first critical speed $W_{\mathrm{cl}}$, no air bubble appears in the tube, but "air caves" reside on the leading sides of both branches (Fig. 11(a)). As $W$ approaches $W_{\mathrm{cl}}$, the air cave in Branch $\mathrm{A}$ reaches the tube, while that in Branch B vanishes. This phenomenon was illustrated by Cheng and Yang (1996). In both cases $Q_{\mathrm{B}}$ increases to the maximum which exceeds the corresponding $Q_{\mathrm{A}}$.

At $W=W_{\mathrm{cl}}$, air bubbles are formed at the downstream side of the Branch A root (Figs. 3(a), 6(a) and 8(a)). The bubbly flow chokes flow passage and causes $Q_{\mathrm{B}}$ in both cases to reduce slightly, while $Q_{\text {A }}$ rises (Fig. 9). Each time two or three bubbles pass the midway of the tube, more air bubbles are introduced into the tube. At a higher $W$, consecutive bubbles ranging from $1 / 8$ to $5 / 16$ inch in diameter fill the whole tube and begin to decrease $Q_{\text {B }}$ in both cases (Figs. 6(b) and 8(b)). 


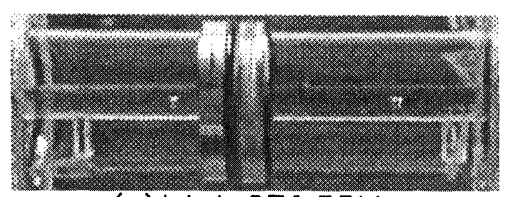

(a) WC $1=970$ RPM

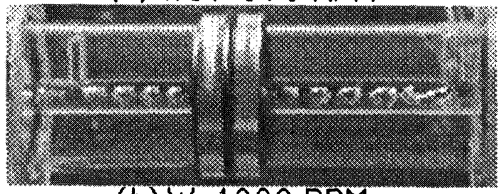

(b) $W=1000$ RPM

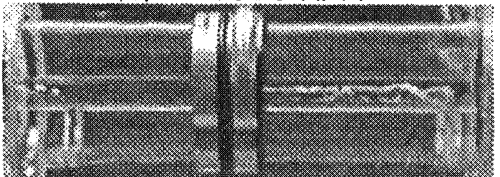

(c) Wc2 $=1050$ RPM, $+0.500 \mathrm{sec}$

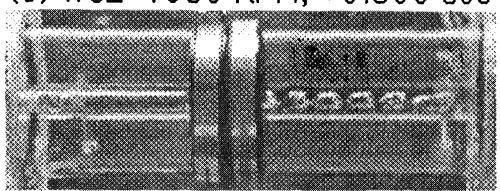

(d) WC2 $=1050$ RPM, $+4.000 \mathrm{sec}$

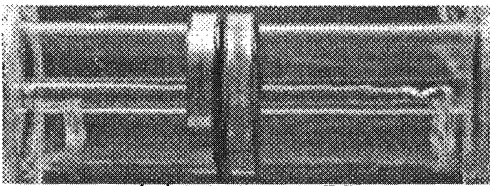

(e) $W=1100$ RPM
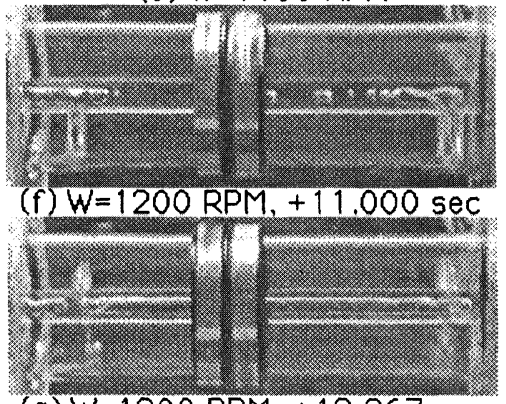

(g) $W=1200$ RPM, $+12.967 \mathrm{sec}$

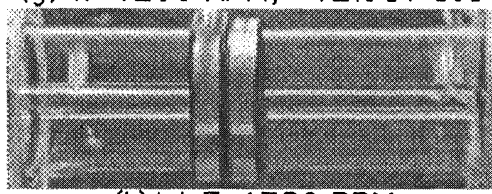

(h) $W C 3=1320$ RPM

FIGURE 6 Flow patterns inside tube in spin-up process (Case 2) $\left(D_{i n}=\frac{1}{4}, d_{S}=\frac{1}{2}{ }^{\prime \prime}, d_{A}=\frac{1}{4}{ }^{\prime \prime}, d_{B}=\frac{1}{8}{ }^{\prime \prime} ; Q<Q_{T-i n i}=0.3\right.$ GPM).

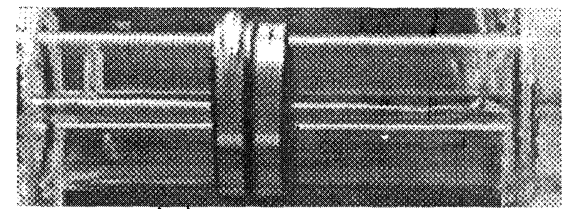

(a) $W=1000$ RPM

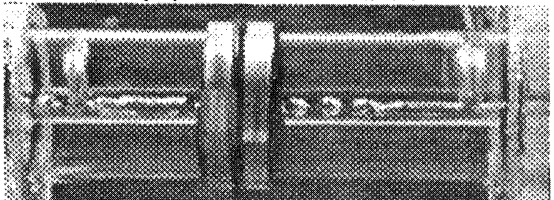

(b) WC 4=970 RPM

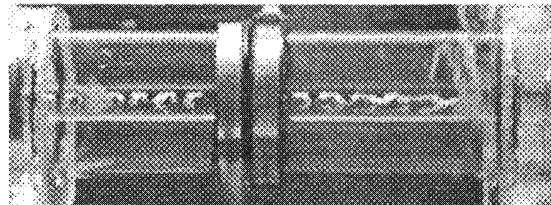

(c) WC5 $=950$ RPM

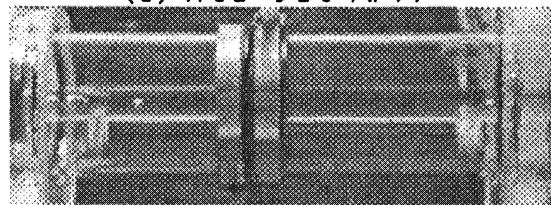

(d) $W C 6=920$ RPM

FIGURE 7 Flow patterns inside tube in spin-down process (Case 2).

At $W=W_{\text {c2 } 2}$ (around $1050 \mathrm{rpm}$ ), bubbles quickly accumulate to form several air pockets in the tube (Figs. 3(b)-(c) and 6(c)-(d)). Beyond the moment when the pockets shrink and the first bubble reaches the Branch $\mathrm{B}$ root, no more bubbles are introduced until the last one enters Branch B. For both cases $Q_{\mathrm{B}}$ falls lower with a rise in $Q_{\mathrm{A}}$ (Fig. 9). An air cavity occupies almost the entire flow passage of Branch A (Fig. 5), and the size of the oil stream on the trailing side varies with the forma- tion of air bubbles. Meanwhile, a moving air pocket exits through Branch B with little change in the size of the oil stream.

When $W$ is higher, an air pocket stays in the tube between the twin branches (Figs. 3(d) and 6(e)). At $1200 \mathrm{rpm}$, Case 1 keeps such a pocket, leading to a regular decrease in $Q_{\mathrm{B}}$. For Case 2, however, the pocket breaks and shrinks downstreamwise, leaving some space with only single-phase oil flow before the next pocket fills in the tube (Figs. 6(f) $-(\mathrm{g})$ ). 


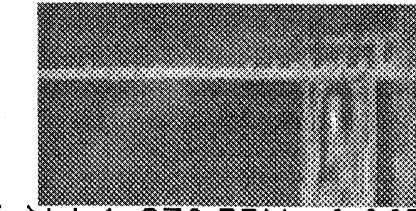

(a) WC $1=970$ RPM, $-0.067 \mathrm{sec}$

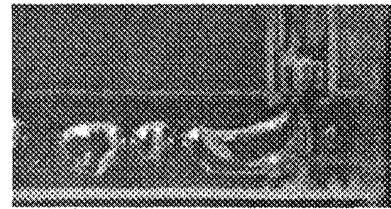

(b) $W=1000$ RPM

FIGURE 8 Flow patterns around Branch $\mathrm{A}$ in spin-up process (Case 2).

(a)

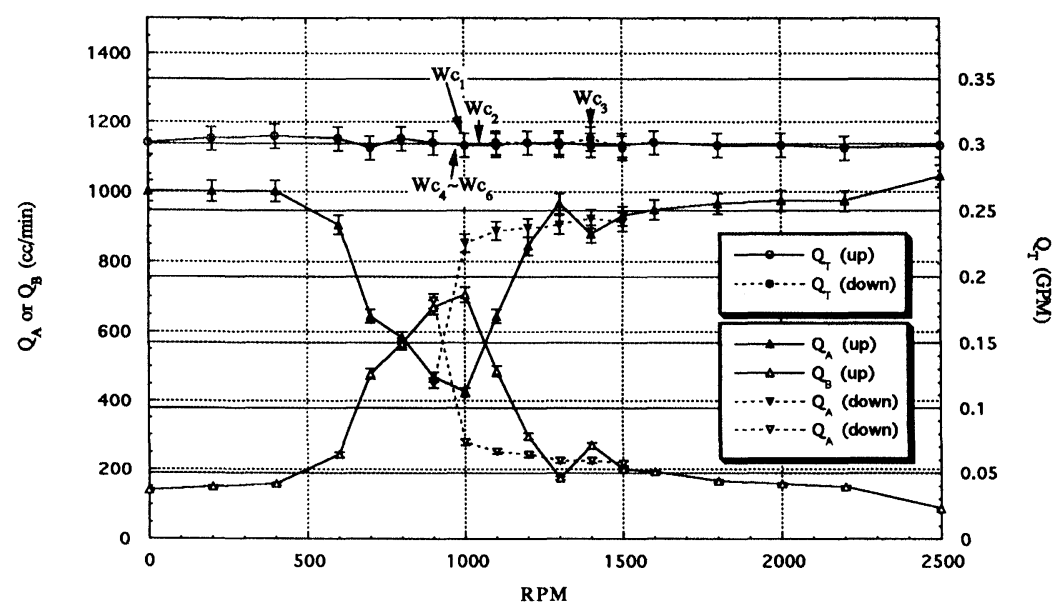

(b)

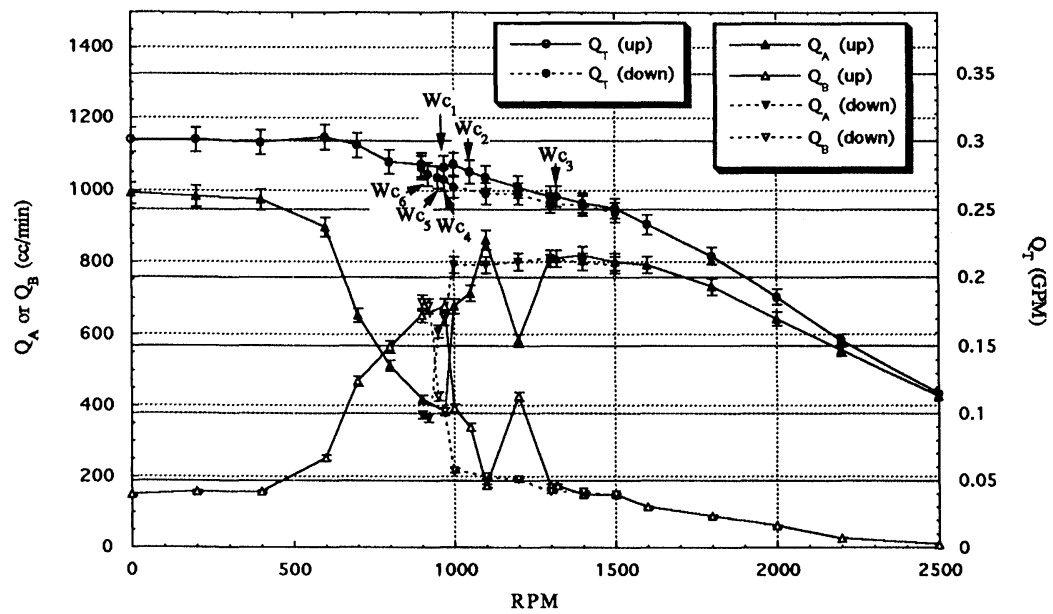

FIGURE 9 Flow rates versus rotational speed for (a) Case 1, (b) Case 2.

The average $Q_{\mathrm{A}}$ drops but it is still more than $Q_{\mathrm{B}}$ (Fig. 9). At $1300 \mathrm{rpm}$, the pocket head of Case 1 extends a little upstreamwise although $Q_{\mathrm{A}}$ reaches a value close to what is measured at $0 \mathrm{rpm}$. The single-phase flow space of Case 2 reduces and $Q_{\mathrm{B}}$ falls sharply.
At $W_{\mathrm{c} 3}$, air-oil flow becomes annular throughout the whole tube. Air is induced into the core and is carried downstreamwise due to interfacial friction. The oil stream on the trailing side shrinks to a rivulet with scattered oil droplets inside Branch B. For Case $1, W_{\mathrm{c} 3}$ is at $1400 \mathrm{rpm}$ (Fig. 3(e)). $Q_{\mathrm{A}}$ 


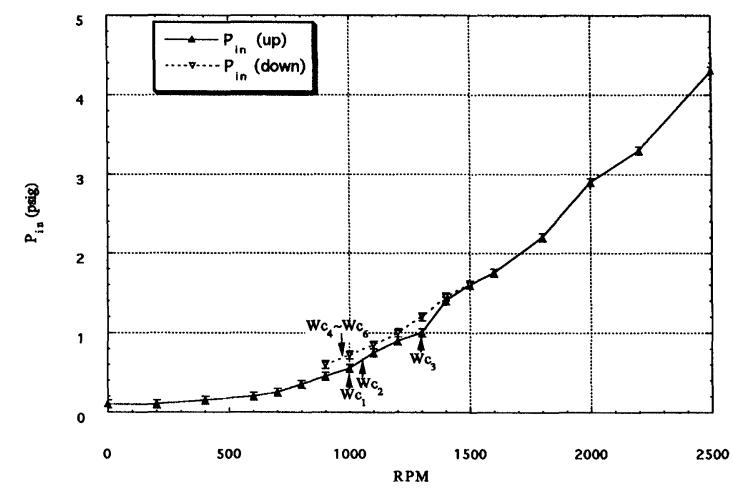

(a)

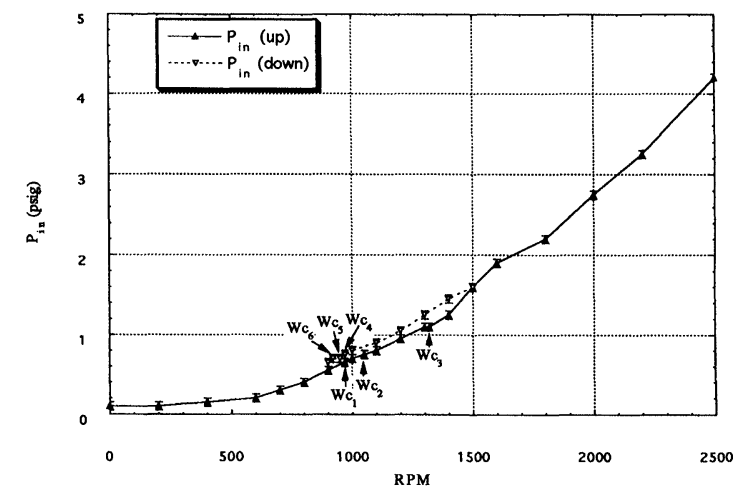

(b)

FIGURE 10 Inlet pressure versus rotational speed for (a) Case 1, (b) Case 2 .

decreases while $Q_{\mathrm{B}}$ increases because some of the oil flow is blocked with the air core to enter Branch A. Beyond $W_{\mathrm{c} 3}, Q_{\mathrm{A}}$ has a trend to approach $Q_{\mathrm{T}}$ (Fig. 9(a)). For Case 2, $W_{\mathrm{c} 3}$ is lower at $1320 \mathrm{rpm}$ (Fig. 6(h)). $Q_{\mathrm{A}}, Q_{\mathrm{B}}$ and $Q_{\mathrm{T}}$ all decrease as $W$ increases (Fig. 9(b)). The oil layer in the tube becomes thinner, and eventually becomes invisible to measure $Q_{\mathrm{B}}$ (Fig. 3(f)).

In the spin-down process, the air-oil annular flow in the tube can be sustained at $W_{\mathrm{s}}$ lower than $W_{\mathrm{c} 2}$ (Figs. 4 and 7). $Q_{\mathrm{A}}$ and $Q_{\mathrm{B}}$ vary slightly prior to another critical speed (Fig. 9). For both cases, the air core between the branches is flushed out, while the remaining air in the upstream tube in front of Branch A gradually breaks into bubbles. The difference is that Case 2 has a $W_{\mathrm{c} 4}$ (around
$970 \mathrm{rpm}$ ) when the air core still remains at a certain distance downstream of the Branch A root, causing air bubbles to congregate into pockets in the downstream tube (Fig. 7(b)). It results in a bubbly flow at $W_{\mathrm{c} 5}=950 \mathrm{rpm}$ (Fig. $\left.7(\mathrm{c})\right)$ and a singlephase oil flow at $W_{\mathrm{c} 6}=920 \mathrm{rpm}$ (Fig. 7(d)). In Case 1, however, transitions from annular to bubbly-slug flow and to single-phase flow are hard to distinguish at about $W_{\mathrm{c} 6}=970 \mathrm{rpm}$ (Figs. 4(b)(d)). These phenomena are accompanied by abrupt changes in $Q_{\mathrm{A}}$ and $Q_{\mathrm{B}}$ (Fig. 9). Below $W_{\mathrm{c} 6}$ the flow rates are about the same as those measured in the spin-up process.

In summary, bubbly and annular types of oil flow are observed in the horizontal rotating tube. Cavitation is induced by outside air entering through Branch A into the tube. This is in contrast to the cavitation of Ishihara (1985) which is generated by flow through a constriction inside a stationary hydraulic system due to pressure drop. Furthermore, hysteresis between spin-up and spindown processes prevails in both cases with or without constant total oil flow rate. The study has disclosed that rotation causes the number of flow patterns to reduce from four (in stationary case) to two, i.e., bubbly and annular flow. This situation is equivalent to flow regimes in the high mass velocity region in Baker's plot (Wallis, 1969) flow-regime correlation in adiabatic horizontal two-phase flow.

The experimental results are consistent with two parameters: the rotational Reynolds number and the Rossby number. The former is defined as the ratio of the Coriolis force to the viscous force, and the latter as the ratio of the Coriolis force in the rotational direction to the inertia force in the flow direction. The rotational Reynolds number explains why a higher rotational speed is required to overcome oil viscosity and separate oil flow from the leading side of each branch. The Rossby number justifies the cause of lean oil flow when an air cavity appears inside the branches: once the Coriolis force dominates, oil flow is forced to the trailing side which corresponds to the high pressure side in single-phase flow. 


\section{CONCLUSIONS}

1. In general, $Q_{\mathrm{T}}$ decreases with an increase in $W$ if operating conditions are unvaried.

2. $P_{\text {in }}$ increases quadratically with an increase in $W$ because of the centrifugal force in the radially rotating entrance branch.

3. $Q_{\mathrm{A}}$ and $Q_{\mathrm{B}}$ are affected by the Coriolis force acting on the radially rotating exit branches.

4. In the spin-up process, air bubbles are introduced at $W_{\mathrm{cl}}$ from open air, through either exit branch against the ejecting oil flow, and into the horizontal rotating tube. The intruding air may block the flow passage and reduce $Q_{\mathrm{B}}$. At $W_{\mathrm{c} 2}$, the air can accumulate to form air pockets as a bubbly-slug flow in the tube, and $Q_{\mathrm{B}}$ increases. Beyond $W_{\mathrm{c} 3}$, an annular flow with air in the core of the tube is observed, and $Q_{\mathrm{B}}$ decreases with an increase in $W$.

5. In the spin-down process, both $Q_{\mathrm{A}}$ and $Q_{\mathrm{B}}$ vary slightly as an annular flow exists in the tube. At $W_{\mathrm{c} 4}$, which may be lower than $W_{\mathrm{c} 2}$, the air core breaks and air in the tube is flushed downstreamwise. However, there may exist an insignificant difference between $W_{\mathrm{c} 4}$ and $W_{\mathrm{c} 5}$, where a bubbly flow appears. For a constant $Q_{\mathrm{T}}$ case, $W_{\mathrm{c} 6}$ comes slightly below $W_{\mathrm{c} 5}$ and the flow pattern resumes single-phase type. But for a varying $Q_{\mathrm{T}}$ case, $W_{\mathrm{c} 6}$ can be far below $W_{\mathrm{c} 5}$.

6. $P_{\text {in }}$ in the spin-down process is higher than that in the spin-up process between $W_{\mathrm{c} 3}$ and $W_{\mathrm{c} 6}$ because the air core built by the annular flow blocks the incoming oil flow through the entrance branch in the tube.

\section{NOMENCLATURE}

$P \quad$ gauge pressure

$Q \quad$ oil volumetric flow rate

Re Reynolds number $=u d / \nu$

Ro Rossby number $=\pi W d / 30 u$

$W \quad$ rotational speed (in $\mathrm{rpm}$ ) $d \quad$ inner diameter

$l \quad$ distances between branches $\mathrm{A}$ and $\mathrm{B}$ and between A and entry

$u$ average velocity

$\nu \quad$ kinetic viscosity of oil (torque fluid, $\left.12.99 \mathrm{~mm}^{2} / \mathrm{s} @ 32^{\circ} \mathrm{C}\right)$

$\rho \quad$ density of oil (torque fluid, $0.815 \mathrm{~g} / \mathrm{cc}$ (a) $32^{\circ} \mathrm{C}$ )

\section{Subscripts}

A upstream exit branch

B downstream exit branch

T total

T-ini total at initial state $(0 \mathrm{rpm})$

c1 transition from single-phase flow to bubbly flow

c2 transition from bubbly flow to bubbly-slug flow

c3 transition from bubbly-slug flow to annular flow

c4 transition from annular flow to bubbly-slug flow

c5 transition from bubbly-slug flow to bubbly flow

c6 transition from bubbly flow to single-phase flow

in entrance branch

$\mathrm{s}$ horizontal rotating tube

\section{References}

Backe, W. and Riedel, H.-P. (1972) Kavitation in Oelhydraulishen Systemen (Cavitation in Oil-Hydraulic Systems), Industrie-Anzeiger, 94(8), 153-158.

Backe, W. (1973) Ein Neues Konzept Fuer Hydraulishe Widerstandssteuerungen (New Concept for Hydraulic Resistance Controls), Industrie-Anzeiger, 95(53), 1137-1141 for part 1 and 95(62), 1431-1434 for part 2 .

Cheng, Sun-Wen and Yang, Wen-Jei (1996) Visualization of oilcavitation flow in a rotating horizontal tube with twin exit branches, Proceedings of the ASME Fluids Engineering Division Summer Meeting, San Diego, USA, July 7-11, 1996, Vol. 4, pp. 17-21.

Ishihara, T., Tanaka, H. and Kojima, E. (1975) Dynamic characteristics of oil-hydraulic pressure control valves, Bulletin of JSME, 18(122), 858-865.

Ishihara, T., Ouchi, M., Kobayashi, T. and Tanura, N. (1979) An experimental study on cavitation in unsteady oil flow, Bulletin of JSME, 22(170), 1099-1106. 
Ishihara, T. (1985) Selected Papers on Automatic Power Transmission, Institute of Industrial Science, University of Tokyo, Japan.

Kojima, M., Fukumura, K. and Yasue, H. (1991) A study on the lubricating oil flow in the automatic transmission, SAE paper 910801.

Riedel, H.-P. (1972) Kavitationsverhalten von Verschiedenen Druckfluessigkeiten (Cavitation Behavior of Various Pressure Fluids), Industrie-Anzeiger, 94(71), 1724-1727.
Shchukin, V.K. (1967) Hydraulic resistance of rotating tubes, Journal of Engineering Physics, 12(6), 782-787.

Wallis, G.B. (1969) One-Dimensional Two-Phase Flow, McGraw-Hill, New York, Chap. 11, pp. 316-317.

White, A. (1964) Flow of a fluid in an axially rotating pipe, Journal of Mechanical Engineering Science, 6(1), 47-52. 


\section{ait \\ ENERGY MATERIALS}

M A N E Y publishing

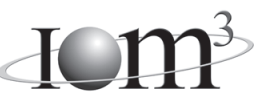

\section{Materials Science \& Engineering for Energy Systems}

Maney Publishing on behalf of the Institute of Materials, Minerals and Mining

The Institute of Materials, Minerals \& Mining

Economic and environmental factors are creating ever greater pressures for the efficient generation, transmission and use of energy. Materials developments are crucial to progress in all these areas: to innovation in design; to extending lifetime and maintenance intervals; and to successful operation in more demanding environments. Drawing together the broad community with interests in these areas, Energy Materials addresses materials needs in future energy generation, transmission, utilisation, conservation and storage. The journal covers thermal generation and gas turbines; renewable power (wind, wave, tidal, hydro, solar and geothermal); fuel cells (low and high temperature); materials issues relevant to biomass and biotechnology; nuclear power generation (fission and fusion); hydrogen generation and storage in the context of the 'hydrogen economy'; and the transmission and storage of the energy produced.

As well as publishing high-quality peer-reviewed research, Energy Materials promotes discussion of issues common to all sectors, through commissioned reviews and commentaries. The journal includes coverage of energy economics and policy, and broader social issues, since the political and legislative context influence research and investment decisions.

\section{CALL FOR PAPERS}

Contributions to the journal should be submitted online at http://ema.edmgr.com

To view the Notes for Contributors please visit: www.maney.co.uk/journals/notes/ema

Upon publication in 2006, this journal will be available via the Ingenta Connect journals service. To view free sample content online visit: www.ingentaconnect.com/content/maney

For further information please contact:

Maney Publishing UK

Tel: +44 (0)113 2497481 Fax: +44 (0)1132486983 Email: subscriptions@maney.co.uk

or

Maney Publishing North America

Tel (toll free): 8662975154 Fax: 6173546875 Email: maney@maneyusa.com

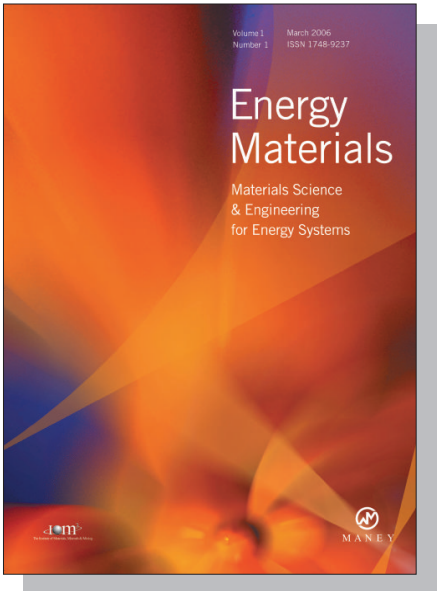

EDITORS

Dr Fujio Abe

NIMS, Japan

Dr John Hald, IPL-MPT, Technical University of Denmark, Denmark

Dr R Viswanathan, EPRI, USA

\section{SUBSCRIPTION INFORMATION}

Volume 1 (2006), 4 issues per year

Print ISSN: 1748-9237 Online ISSN: 1748-9245

Individual rate: $£ 76.00 / U S \$ 141.00$

Institutional rate: $£ 235.00 /$ US $\$ 435.00$

Online-only institutional rate: $£ 199.00 / U S \$ 367.00$

For special $\mathrm{IOM}^{3}$ member rates please email

subscriptions@maney.co.uk

\section{For further information or to subscribe online please visit www.maney.co.uk}



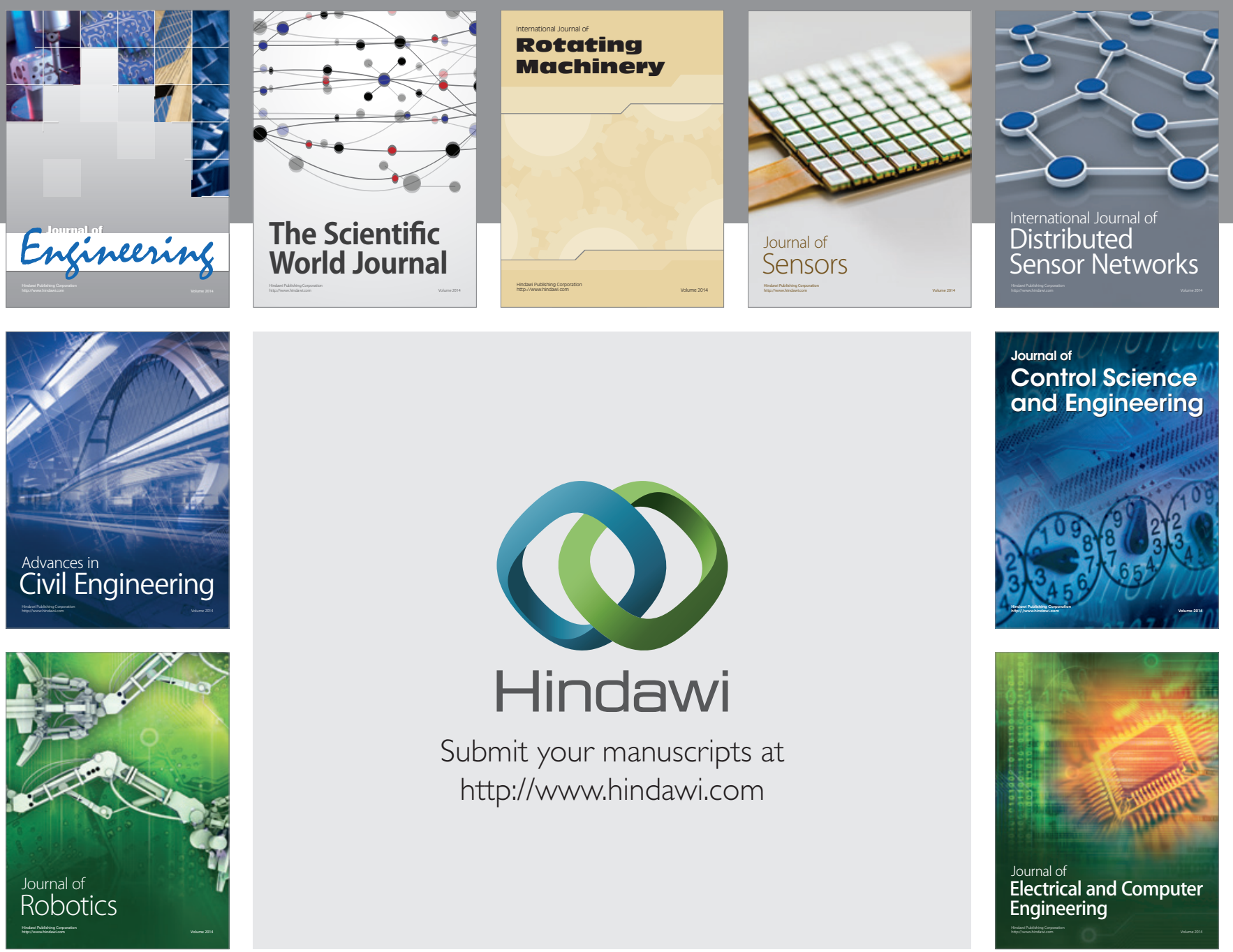

Submit your manuscripts at

http://www.hindawi.com
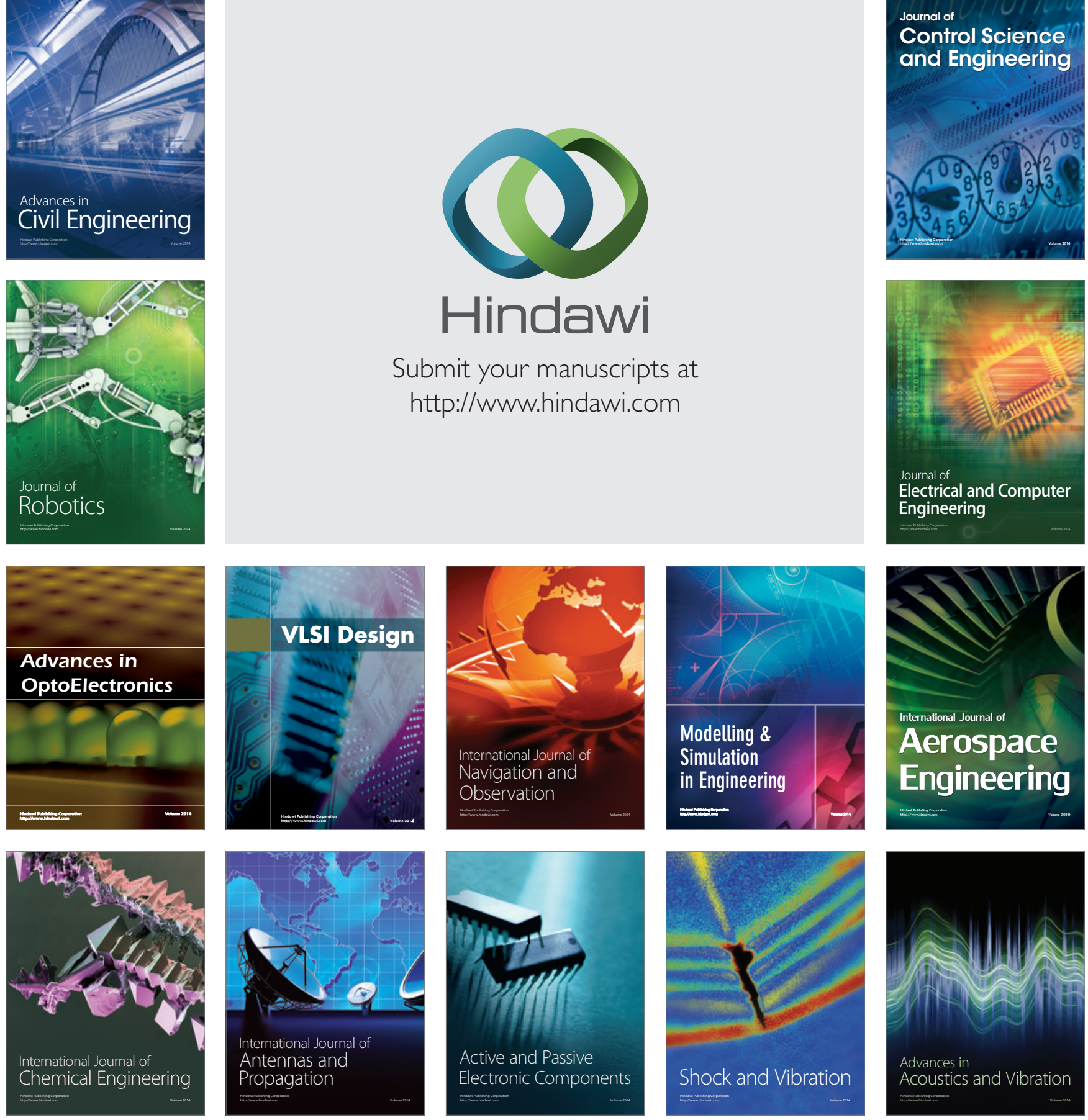